\title{
The benefit of pharmacological venous thromboprophylaxis in foot and ankle surgery
}

\author{
N P Saragas, ${ }^{1,2}$ MB BCh, FCS (SA) Orth, MMed (Orth Surg); P N F Ferrao, ${ }^{1,2}$ MB ChB, FCS (SA) Orth; B F Jacobson, ${ }^{3}$ MB ChB, MMed (Haem), \\ FRCS (Glasg), FC Path (SA), PhD (Med); E Saragas, ${ }^{3}$ MB BCh, FFPath (Haem) (SA); A Strydom, ${ }^{1,2}$ MB BCh, FC Orth (SA), MMed (Orth Surg) \\ ${ }^{1}$ Orthopaedic Foot and Ankle Unit, Netcare Linksfield Hospital, Johannesburg, South Africa \\ ${ }^{2}$ Foot and Ankle Unit, Division of Orthopaedic Surgery, Faculty of Health Sciences, University of the Witwatersrand, Johannesburg, South Africa \\ ${ }^{3}$ Department of Molecular Medicine and Haematology, School of Pathology, Faculty of Health Sciences, University of the Witwatersrand, \\ Johannesburg; and National Health Laboratory Service, Johannesburg, South Africa
}

Corresponding author: N P Saragas (saragas@global.co.za)

Background. Ten percent of patients with a deep-vein thrombosis (DVT) will develop a fatal pulmonary embolism (PE), often initially asymptomatic. The risks and benefits of pharmacological thromboprophylaxis are well documented in respect of total joint arthroplasty and hip fractures, but little is understood about the incidence of venous thromboembolism (VTE) or the potential risks and benefits of chemoprophylaxis in foot and ankle surgery.

Objective. To determine whether prophylactic chemoprophylaxis had any impact on the prevention of VTE in a cohort of foot and ankle surgical patients requiring the combination of below-knee cast immobilisation and non-weightbearing for $\geq 4$ weeks.

Methods. Between March 2014 and April 2015, a prospective cohort study of 142 patients was performed. All completed a thrombosis risk assessment form prior to surgery and were commenced on rivaroxaban (Xarelto) $10 \mathrm{mg} / \mathrm{d}$ postoperatively. The primary outcome measure was clinical VTE confirmed by compression ultrasonography (DVT) or a ventilation/perfusion scan (PE).

Results. Three patients (2.1\%) developed a clinical DVT. Two did so well beyond the immobilisation and anticoagulation period, and one was non-compliant with therapy. The average risk factor score in this subgroup was 7. No patient had a DVT while on the prescribed regimen of anticoagulant therapy. Five patients (3.5\%) developed wound breakdown, two requiring surgical debridement with local skin flap closure. One case of menorrhagia that may have been linked to the anticoagulant therapy was reported. When compared with a previous study, pharmacological thromboprophylaxis significantly reduced VTE risk $(p=0.02)$.

Conclusions. Oral pharmacological thromboprophylaxis significantly reduces the risk of VTE in patients requiring cast immobilisation and non-weightbearing following foot and ankle surgery. The risk/benefit ratio favours this treatment as opposed to the treatment of major morbidity following non-fatal VTE.

S Afr Med J 2017;107(4):327-330. DOI:10.7196/SAMJ.2017.v107i4.10843

Approximately two million people develop deep-vein thrombosis (DVT) annually, and of these an estimated 200000 die from a fatal pulmonary embolism (PE). ${ }^{[1]}$ Fifty percent of these cases are 'silent', and the first sign or symptom of venous thromboembolic disease (VTED) is a fatal PE. ${ }^{[2]}$

VTED accounts for $10 \%$ of all hospital deaths, ${ }^{[3]}$ and approximately 1 in 20 hospitalised medical patients may develop a fatal PE if they have not received appropriate thrombosis prophylaxis. ${ }^{[4]}$

If not fatal, untreated venous thromboembolism (VTE) may have serious consequences such as risk of recurrent VTE, ${ }^{[1]}$ postthrombotic syndrome, ${ }^{[1]}$ chronic thromboembolic pulmonary hypertension ${ }^{[5]}$ and reduced quality of life. ${ }^{[6]}$

The prevalence of VTE and the use of pharmacological thromboprophylaxis in total hip replacement (THR), total knee replacement (TKR) and hip fractures have been well documented in published literature and in clinical trials. ${ }^{[1,7-10]}$

Although there is potentially an increased risk of VTE in foot and ankle surgery, the incidence of VTE is poorly understood. None of the available studies are comparable owing to non-uniformity of the patient populations, failure to distinguish between symptomatic and silent thrombosis, the considerable diversity in foot and ankle pathology, and varying aftercare protocols, which may be why the reported incidence of VTE after foot and ankle surgery ranges widely, from $0 \%$ to $36 \%{ }^{[11-34]}$
A database study in the National Health Service in the UK found that the rate of symptomatic VTED following ankle fracture surgery, total ankle replacement, hindfoot arthrodesis or first metatarsal surgery was $<0.3 \%$ for each type of surgery. ${ }^{[34]}$ Mizel et al. ${ }^{[21]}$ found prevalences of symptomatic DVT and non-fatal PE of $0.22 \%$ and $0.15 \%$, respectively.

In a prospective study using colour duplex Doppler ultrasonography, we found a $1 \%$ incidence of DVT in 100 patients following hallux surgery. ${ }^{[35]}$ Lapidus et al., ${ }^{[36]}$ however, found a $28 \%$ DVT rate in patients after ankle fracture surgery who did not receive pharmacological prophylaxis. In two studies following Achilles tendon rupture repair, the incidences of DVT were $36 \%{ }^{[19]}$ and $6 \% .{ }^{[26]}$

In a more recent prospective study, we found an $8.5 \%$ incidence of VTE in patients who required immobilisation in a below-knee cast and non-weightbearing for $\geq 4$ weeks after foot and ankle surgery. ${ }^{[37]}$ Two patients developed a PE. Neither of them had shown any clinical evidence of DVT.

Although the majority of recent studies do not advocate the routine use of chemoprophylaxis in foot and ankle surgery, ${ }^{[6,12,13,21,22,25,27,30,33,38-40]}$ several authors recommend its use in patients with identifiable specific clinical risk factors. ${ }^{[6,8-20,26,37,41]}$ A difficulty of long-term follow-up of patients is that many DVT events occur several weeks or longer after discharge. ${ }^{[37,42]}$ 
In the case of post-thrombotic syndrome, which may affect $20-50 \%$ of patients diagnosed with DVT, most symptoms become apparent within 2 years of developing DVT. ${ }^{[43]}$ VTE is essentially a disease with short-term mortality and long-term morbidity.

\section{Objective}

To determine whether prophylactic chemoprophylaxis had any impact on the prevention of VTE in a cohort of foot and ankle surgical patients requiring the combination of below-knee cast immobilisation and nonweightbearing for $\geq 4$ weeks, identified by us as a risk factor for VTE in a previous study, ${ }^{[37]}$ and therefore whether its routine administration is justified in these selected patients.

The primary outcome measure was the development of clinical VTE, including infrapopliteal DVT, proximal DVT and PE. Proximal DVT and PE are the potentially fatal conditions, but infrapopliteal DVT may have serious consequences, as outlined above.

At the time of the study, two direct oral anticoagulants were readily available. Rivaroxaban (Xarelto; Bayer) was chosen arbitrarily.

\section{Methods}

All patients aged $>18$ years who underwent foot and ankle surgery requiring the combination of below-knee immobilisation in a cast and non-weightbearing for $\geq 4$ weeks were included in this prospective study. Patients who were already on anticoagulants or had previously had a DVT were excluded. During the period March 2014 -April 2015, 142 consecutive patients who met the criteria were identified. No patient refused to participate.

After giving informed consent, every patient included in the study received rivaroxaban $10 \mathrm{mg}$ orally for $4-6$ weeks, i.e. until he or she no longer required nonweightbearing or cast immobilisation (whichever one came first). The first dose was given at $06 \mathrm{~h} 00$ on the first day postoperatively, and the drug was administered 24-hourly thereafter.

Before the operation, all patients completed a thrombosis risk assessment form (Fig. 1), adapted from Caprini[ ${ }^{[41]}$ and endorsed by the Southern African Society of Thrombosis and Haemostasis. The higher the score, the higher is the risk of developing a DVT. Tourniquet time, procedure groups and smoking were included as possible risk factors. The above risk factors were identified so that the present study would be

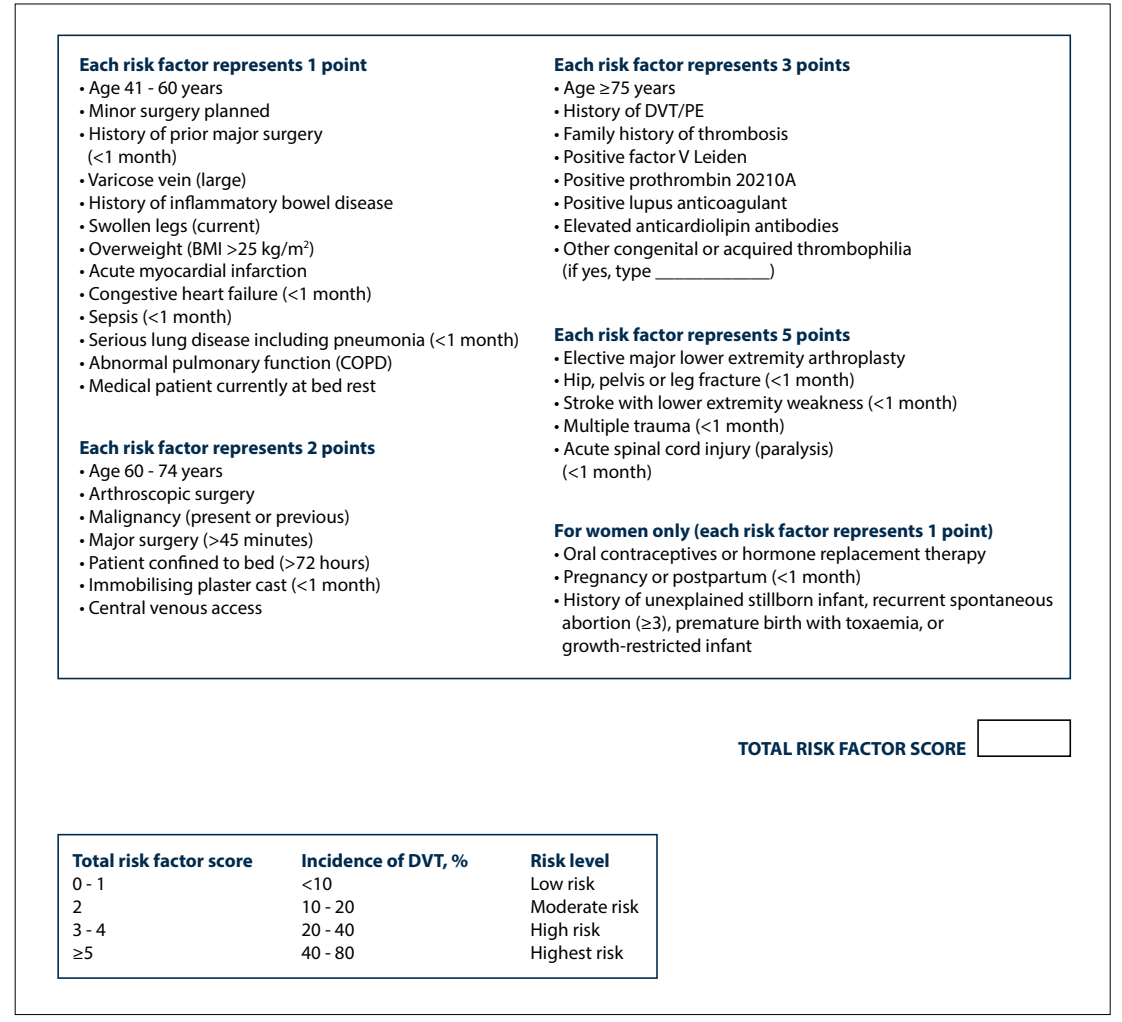

Fig. 1. Thrombosis risk factor assessment. (COPD = chronic obstructive pulmonary disease.)

comparable with our previous study, ${ }^{[37]}$ in which no patient had received any venous thromboprophylaxis postoperatively.

The primary outcome measure was the development of a clinically evident DVT, as confirmed by compression ultrasonography or a ventilation/perfusion lung scan in the case of PE.

Ethics approval was obtained from the Human Research Ethics Committee (Medical) of the University of the Witwatersrand, Johannesburg (ref. no. M131165).

\section{Results}

There were 75 male and 67 female patients, with a mean age of 50.9 years (range 20 78). Table 1 summarises the procedure groups. The average body mass index (BMI) $\left(\mathrm{kg} / \mathrm{m}^{2}\right)$ was 29 (range $\left.18-55\right)$ and the average risk factor score was 7 (range 3 - 15). Fourteen patients $(9.9 \%)$ were smokers or had smoked within 1 year prior to surgery. Average tourniquet time was 86 minutes (range 33 - 150).

Three patients $(2.1 \%)$ developed a clinically evident DVT, confirmed by compression ultrasonography. Two were extensive (proximal to the calf). One patient developed a clinical DVT 5 weeks after an acute Achilles tendon rupture repair. He admitted being non-compliant in taking his anticoagulation, which had been prescribed for 4 weeks. The other two patients (triple fusion and ankle arthrodesis) developed a DVT at 9 weeks and 14 weeks, respectively, well after completion of the prophylactic anticoagulant, which had been prescribed for 6 weeks.

Five patients $(3.5 \%)$ developed wound breakdown and were referred to a plastic surgeon. Two required major debridement (internal fixatives were not removed) and closure with a local skin flap. The remaining three were treated with appropriate dressings.

One patient developed menorrhagia, which may have been related to the anticoagulant. The drug was stopped until the menorrhagia abated, and then resumed.

Two patients stopped taking their anticoagulant a few days after surgery because they suspected that there was bleeding under the cast. When the cast was removed no active bleeding was noted, and the drug was resumed within 2 weeks following surgery.

One of the three patients who developed a DVT was a smoker. The average risk factor score in these three patients was 7 (range 6 8) v. 7.7 (range 4 - 13) in the VTE group in our previous study, ${ }^{[37]}$ in which the average BMI was 34 (range $32-36$ ). The average tourniquet time in the previous study was 92 minutes (range 55 - 120). The numbers were too small for statistical analysis.

None of the above three patients developed a clinically evident DVT while they were receiving the anticoagulant. 


\begin{tabular}{ll} 
Table 1. Operative procedures included in the study \\
\hline Procedure & Patients, $\boldsymbol{n}$ \\
\hline Hindfoot arthrodesis & 22 \\
Mid-foot arthrodesis & 19 \\
Acquired flat-foot correction & 18 \\
Achilles tendon rupture repair & 17 \\
Ankle arthrodesis + tibiotalocalcaneal arthrodesis & 16 \\
Achilles tendon debridement and repair & 11 \\
Tendon (other than Achilles tendon) & 7 \\
debridement/repair & \\
Total ankle replacement & 7 \\
Lateral ligament reconstruction & 5 \\
Dwyer calcaneal osteotomy & 4 \\
Ankle fracture ORIF & 4 \\
OATS & 2 \\
Lisfranc ORIF & 2 \\
Jones fracture ORIF & 2 \\
Gastrocnemius recession & 2 \\
Dislocating peroneal tendons & 2 \\
Tendon transfers & 1 \\
Non-union tibia (revision) & 1 \\
ORIF open reduction and internal fixation; OATS = osteochondral autogenous \\
transplantation system.
\end{tabular}

\section{Discussion}

Little has been written on the development and prophylaxis of VTE in foot and ankle surgery. Individual patient- and procedure-specific risk factors have been implicated in the development of VTE. ${ }^{[37]}$ The more universally accepted risk factors have been adopted by Caprini ${ }^{[41]}$ and are widely used worldwide.

The concern about using anticoagulation is possible adverse events. These have been thoroughly investigated in clinical trials using TKR, THR and hip fracture models, with figures of $2.9-6.5 \%$ for nonmajor bleeding, $0.6-1.0 \%$ for wound-related infections, $<0.1-4.9 \%$ for major bleeding, $0-0.4 \%$ for cerebrovascular adverse events, and $0-1.4 \%$ for death from any cause. ${ }^{[7-10]}$ The decision whether or not to use thrombosis chemoprophylaxis is therefore decided by weighing up the patient's risk for bleeding against the risk of developing VTE. No universal guidelines are available, although the general consensus from various bodies ${ }^{[31,34,38,40]}$ and published articles ${ }^{[6,12,13,21,22,24,25,27,30,33,39]}$ is that use of prophylactic anticoagulation is not advocated in foot and ankle surgery

In a previous prospective study, ${ }^{[37]}$ we found that the absolute number of cases of VTE after foot and ankle surgery was unacceptably high $(11 / 130(8.5 \%))$, although this was not statistically significant owing to the relatively small number of cases. We identified a cohort of patients who were particularly prone to developing VTE after foot and ankle surgery. They did not have individual or procedure-specific risk factors per se, but were a group requiring the combination of cast immobilisation and non-weightbearing for a period of $\geq 4$ weeks. Using the $\chi^{2}$ test with a level of significance of $p<0.05$, the present study demonstrated that the incidence of DVT $(2.1 \%)$ decreased significantly from $8.5 \%{ }^{[37]}(p=0.01)$ when prophylactic anticoagulation was given.

It is also important to note that one of the three patients who developed a DVT was non-compliant, and the other two developed a DVT several weeks after completion of the prophylactic anticoagulation.

Adverse events possibly caused by the anticoagulant were superficial wound sepsis $(3.5 \%)$ and menorrhagia $(0.7 \%)$. Procedures in the patients who developed superficial sepsis requiring a skin graft in theatre were a triple fusion, mid-tarsal fusion and non-union of the tibia, with an average risk factor score of 7 (range 6 - 8). There were no smokers in this group.

We appreciate the disadvantage of rivaroxaban as a potential cause of bleeding, particularly in emergency 'second-look' surgery. However, such an emergency rarely occurs in foot and ankle surgery, and in the infrequent case when a second-look procedure is required in a patient receiving rivaroxaban $10 \mathrm{mg} / \mathrm{d}$, a waiting period of 8 hours will suffice. If more urgent intervention is needed, a readily available procoagulant can be administered.

Rivaroxaban $10 \mathrm{mg}$ film-coated tablets are indicated for the prevention of VTE in patients undergoing major orthopaedic surgery of the lower limbs. Although all the clinical trials have been limited to TKR, THR and hip fracture surgery, we considered that the same regimen would be adequate and safe in patients undergoing foot and ankle surgery where anticoagulation was indicated. Furthermore, the choice of using this mode of prophylaxis over the standard low-molecular-weight (LMW) heparin injection was the ease of administration and the cost factor (a $40 \mathrm{mg}$ LMW heparin injection is approximately three times the price of $10 \mathrm{mg}$ rivaroxaban as a once-daily dose).

Study limitations are the relatively small number of patients, the lack of routine postoperative duplex Doppler studies (therefore missing silent DVTs), and the absence of a concurrent study as control.

\section{Conclusions}

The current study was initiated 2 years after conclusion of the previous study by the same senior surgeons. The methodology, demographics, mode of anaesthesia and risk factors were comparable. On the basis of the previous study, we consider that a group of patients has been identified who will probably benefit from receiving prophylactic anticoagulation in foot and ankle surgery. We noted a significant decrease in the risk of developing VTE in patients requiring a combination of cast immobilisation and non-weightbearing status for a period of $\geq 4$ weeks who received rivaroxaban.

We found that the risk/benefit ratio favours the administration of prophylactic anticoagulation, as the adverse events of such medication are relatively minor compared with life-threatening PE, and in the case of non-fatal VTED, the expense of treatment and long-term morbidity.

The ultimate decision whether or not to offer the patient venous thromboprophylaxis remains the prerogative of the surgeon, whose decision should be based on a case-by-case basis, determining the risk/benefit ratio for the individual patient.

1. Geerts WH, Pineo GF, Heit JA, et al. Prevention of venous thromboembolism: The Seventh ACCP Conference on Antithrombotic and Thrombolytic Therapy. Chest 2004;126(3 Suppl):338S-400S. https://doi.org/10.1378/chest.126.3_suppl.338s

2. Stein PD, Henry JW. Prevalence of acute pulmonary embolism among patients in a general hospital and at autopsy. Chest 1995;108(4):978-981. https://doi.org/10.1378/chest.108.4.978

3. Jacobson BF, Louw S, Mer M, et al. Venous thromboembolism - prophylactic and therapeutic practice guideline. S Afr Med J 2009;99(6):467-468,470-473.

Baglin TP, White K, Charles A. Fatal pulmonary embolism in hospitalised medical patients. J Clin Baglin TP, White K, Charles A. Fatal pulmonary embolism in
Pathol 1997;50(7):609-610. https://doi.org/10.1136/jcp.50.7.609

5. Pengo V, Lensing AW, Prins MH, et al. Incidence of chronic thromboembolic pulmonary hypertension after pulmonary embolism. N Engl J Med 2004;350(22):2257-2264. https://doi.org/10.1056/ NEJMoa032274

6. Kahn SR, Shbaklo H, Lamping DL, et al. Determinants of health-related quality of life during the 2 years following deep vein thrombosis. J Thromb Haemost 2008;6(7):1105-1112. https://doi. org/10.1111/j.1538-7836.2008.03002.x

7. Eriksson B. An introduction to rivaroxaban: The first oral, once-daily, direct factor Xa inhibitor for the prevention of venous thromboembolism. J Bone Joint Surg Br 2008;(Suppl, September):3-6.

8. Eriksson BI, Borris LC, Friedman RJ, et al. Rivaroxaban versus enoxaparin for thromboprophylaxis after hip arthroplasty. N Engl J Med 2008;358(26):2765-2775. https://doi.org/10.1016/j.jvs.2008.07.047 9. Kakkar AK. Rivaroxaban venous thromboembolism risk reduction after total hip arthroplasty. J Bone Joint Surg Br 2008; (Suppl, September):18-23.

10. Turpie AG, Bauer KA, Eriksson BI, Lassen MR. Fondaparinux vs enoxaparin for the prevention of venous thromboembolism in major orthopedic surgery: A meta-analysis of 4 randomized doubleblind studies. Arch Intern Med 2002;162(16):1833-1840. https://doi.org/10.1001/archinte.162.16.1833 
11. Anderson FA jr, Spencer FA. Risk factors for venous thromboembolism. Circulation 2003;107(23 Suppl 1):19-16. https://doi.org/10.1161/01.cir.0000078469.07362.e6

12. Barg A, Knupp M, Anderson AE, Hintermann B. Total ankle replacement in obese patients Component stability, weight change, and functional outcome in 118 consecutive patients. Foot Ankle Component stability, weight change, and functional outcome in
Int 2011:32(10):925-932. https://doi.org/10.3113/fai.2011.0925

13. Griffiths JT, Matthews L, Pearce CJ, Calder JD. Incidence of venous thromboembolism in elective foot and ankle surgery with and without aspirin prophylaxis. J Bone Joint Surg Br 2012;94(2):210-214 https://doi.org/10.1302/0301-620x.94b2.27579

4. Hanslow SS, Grujic L, Slater HK, Chen D. Thromboembolic disease after foot and ankle surgery. Foot Ankle Int 2006;27(9):693-695.

15. Ingvar J, Tagil M, Eneroth M. Nonoperative treatment of Achilles tendon rupture: 196 consecutive patients with a 7\% re-rupture rate. Acta Orthop 2005;76(4):597-601. https://doi. org $/ 10.1080 / 17453670510041619$

16. Jorgensen PS, Warming $\mathrm{T}$, Hansen $\mathrm{K}$, et al. Low molecular weight heparin (Innohep) as thromboprophylaxis in outpatients with a plaster cast: A venografic controlled study. Thromb Res 2002;105(6):477-480. https://doi.org/10.1016/s0049-3848(02)00059-2

17. Kerkhoffs GM, Struijs PA, Raaymakers EL, Marti RK. Functional treatment after surgical repair of acute Achilles tendon rupture: Wrap vs walking cast. Arch Orthop Trauma Surg 2002;122(2):102-105. acute Achilles tendon rupture: Wrap vs
https://doi.org/10.1007/s004020100312

18. Kock HJ, Schmit-Neuerburg KP, Hanke J, Rudofsky G, Hirche H. Thromboprophylaxis with low-molecular-weight heparin in outpatients with plaster-cast immobilisation of the leg. Lancet 1995;346(8973):459-461. https://doi.org/10.1016/s0140-6736(95)91320-3

19. Lapidus LJ, Rosfors S, Ponzer S, et al. Prolonged thromboprophylaxis with dalteparin after surgical treatment of Achilles tendon rupture: A randomized, placebo-controlled study. J Orthop Traum 2007;21(1):52-57. https://doi.org/10.1097/01.bot.0000250741.65003.14

20. Lassen MR, Borris LC, Nakov RL. Use of the low-molecular-weight heparin reviparin to prevent deep-vein thrombosis after leg injury requiring immobilization. N Engl J Med 2002;347(10):726-730. https://doi.org/10.1056/nejmoa011327

21. Mizel MS, Temple HT, Michelson JD, et al. Thromboembolism after foot and ankle surgery A multicenter study. Clin Orthop Relat Res 1998;348(3):180-185.

22. Nilsson-Helander K, Thurin A, Karlsson J, Eriksson BI. High incidence of deep venous thrombosis after Achilles tendon rupture: A prospective study. Knee Surg Sports Traumatol Arthrosc 2009:17(10):12341238. https://doi.org/10.1007/s00167-009-0727-y

23. Patil S, Gandhi J, Curzon I, Hui AC. Incidence of deep-vein thrombosis in patients with fractures of the ankle treated in a plaster cast. J Bone Joint Surg Br 2007;89(10):1340-1243. https://doi. of the ankle treated in a plaster cast.
org $/ 10.1302 / 0301-620 \mathrm{x} .89 \mathrm{~b} 10.19241$

24. Patel A, Ogawa B, Charlton T, Thordarson D. Incidence of deep vein thrombosis and pulmonary embolism after Achilles tendon rupture. Clin Orthop Relat Res 2012;470(1):270-274. https://do org/10.1007/s11999-011-2166-6

25. Radl R, Kastner N, Aigner C, Portugaller H, Schreyer H, Windhager R. Venous thrombosis after hallux valgus surgery. J Bone Joint Surg Am 2003;85-A(7):1204-1208. https://doi.org/10.2106/00004623 200404000-00035

26. Saragas NP, Ferrao PN. The incidence of venous thromboembolism in patients undergoing surgery for acute Achilles tendon ruptures. Foot Ankle Surg 2011;17(4):263-265. https://doi.org/10.1016/ fas. 2010.12 .002

27. Solis G, Saxby T. Incidence of DVT following surgery of the foot and ankle. Foot Ankle Int 2002;23(5):411-414. https://doi.org/10.1177/107110070202300507

28. SooHoo NF, Farng E, Krenek L, Zingmond DS. Complication rates following operative treatment of calcaneus fractures. Foot Ankle Surg 2011;17(4):233-238. https://doi.org/10.1016/j.fas.2010.08.003
29. Stanton T. Routine DVT, PE prophylaxis questionable in foot, ankle surgery. AAOS Now 2011;June:Clinical. http://aaos.org/AAOSNow/2011/Jun/clinical/clinical10/?ssopc=1 (accessed 3 March 2017).

30. Wukich DK, Waters DH. Thromboembolism following foot and ankle surgery: A case series and literature review. J Foot Ankle Surg 2008;47(3):243-249. https://doi.org/10.1053/jijfas.2008.02.003

31. Goldhaber SZ, Tapson VF. A prospective registry of 5,451 patients with ultrasound-confirmed deep vein thrombosis. Am J Cardiol 2004;93(2):259-262. https://doi.org/10.1016/j.amjcard.2003.09.05

32. Kakkar VV, Howe CT, Flanc C, Clarke MB. Natural history of postoperative deep-vein thrombosis. Lancet 1969;2(7614):230-232. https://doi.org/10.1016/s0140-6736(69)92722-6

33. SooHoo NF, Eagan M, Krenek L, Zingmond DS. Incidence and factors predicting pulmonary embolism and deep venous thrombosis following surgical treatment of ankle fractures. Foot Ankle Surg 2011;17(4):259-262. https://doi.org/10.1016/j.fas.2010.08.009

34. Jameson SS, Augustine A, James P, et al. Venous thromboembolic events following foot and ankle surgery in the English National Health Service. J Bone Joint Surg Br 2011;93(4):490-497. https://doi. org/10.1302/0301-620x.93b4.25731

35. Saragas N, Ferrao P, Saragas E, Jacobson B. Venous thromboembolic disease in hallux surgery. SA Orthop J 2014;13(3):28-31.

36. Lapidus LJ, Ponzer S, Elvin A, et al. Prolonged thromboprophylaxis with dalteparin during immobilization after ankle fracture surgery: A randomized placebo-controlled, double-blind study. Acta Orthop 2007;78(4):528-535. https://doi.org/10.1080/17453670710014185

37. Saragas NP, Ferrao PN, Saragas E, Jacobson BF. The impact of risk assessment on the implementation of venous thromboembolism prophylaxis in foot and ankle surgery. Foot Ankle Surg 2014;20(2):85-89. https://doi.org/10.1016/j.fas.2013.11.00

38. Scientific Committee, British Orthopaedic Foot and Ankle Surgery Society. British Orthopaedic Foot and Ankle Society Guidelines for Venous Thromboembolism Prophylaxis. http://bofas.org.uk/News/ News-Details/ArticleId/1/Current-BOFAS-position-statement-on-VTE-prophylaxis-in-foot-andankle-surgery (accessed 20 April 2010)

39. Hamilton PD, Hariharan K, Robinson AH. Thromboprophylaxis in elective foot and ankle patients current practice in the United Kingdom. Foot Ankle Surg 2011;17(2):89-93. https://doi.org/10.1016/j. fas.2011.02.004

40. Fleischer AE, Abicht BP, Baker JR, Boffeli TJ, Jupiter DC, Schade VL. American College of Foot and Ankle Surgeons' clinical consensus statement: Risk, prevention, and diagnosis of venous thromboembolism disease in foot and ankle surgery and injuries requiring immobilization. J Foot Ankle Surg 2015;54(3):497-507. https://doi.org/10.1053/.j.jas.2015.02.022

41. Caprini JA. Thrombosis risk assessment as a guide to quality patient care. Dis Mon 2005;51(2-3):70-78. https://doi.org/10.1016/j.disamonth.2005.02.003

42. Warwick D, Friedman RJ, Agnelli G, et al. Insufficient duration of venous thromboembolism prophylaxis after total hip or knee replacement when compared with the time course of thromboembolic events: Findings from the Global Orthopaedic Registry. J Bone Joint Surg Br 2007;89(6):799-807. https://doi. org/10.1302/0301-620x.89b6.18844

43. Kahn SR, Comerota AJ, Cushman M, et al. The postthrombotic syndrome: Evidence-based prevention, diagnosis, and treatment strategies: A scientific statement from the American Heart Association. Circulation 2014;130(18):1636-1661. https://doi.org/10.1161/cir.0000000000000130

Accepted 12 January 2017 